\title{
A ALTERIDADE NO PLANO PEDAGÓGICO A PARTIR DOS PRESSUPOSTOS DE ENRIQUE DUSSEL
}

\author{
LA ALTERIDAD EN EL PLAN PEDAGÓGICO BASADO EN LOS SUPUESTOS DE \\ ENRIQUE DUSSEL
}

\author{
THE OTHERNESS IN THE PEDAGOGICAL PLAN FROM THE FOUNDATIONS OF \\ ENRIQUE DUSSEL
}

\author{
André Luis Castro de FREITAS ${ }^{1}$ \\ Luciane Albernaz de Araujo FREITAS ${ }^{2}$
}

RESUMO: O texto possui como objetivo tecer aproximações ao pensamento de Enrique Dussel por meio de um estudo descritivo crítico, fundamentado em uma pesquisa qualitativa, bibliográfica. Tem-se como intenção elencar os pressupostos que demonstrem a importância da categoria alteridade no que pese refletir sobre a construção de projetos de vida para o povo latino-americano, aproximando as ideias trabalhadas à área da educação. Reflete-se sobre a passagem da alienação à liberdade, movimento produzido pela libertação pedagógica. Problematiza-se sobre como descrever a experiência da proximidade entre os seres humanos como experiência da história popular e, por fim, reflete-se sobre a importância de destituir os obstáculos que impedem a revelação do Outro, por meio de um pensar que sabe escutar a palavra analética do Outro, comprometendo-se com a palavra reveladora e a sua justa interpretação.

PALAVRAS-CHAVE: Alteridade. Diálogo. Direitos humanos. Educação.

RESUMEN: El texto pretende hacer aproximaciones al pensamiento de Enrique Dussel a través de un estudio descriptivo crítico, basado en una investigación cualitativa, de carácter bibliográfico. La intención es enumerar los supuestos que demuestran la importancia de la categoría de alteridad para reflexionar sobre la construcción de proyectos de vida para los latinoamericanos, acercándose las ideas trabajadas en el área de la educación. Reflexiona sobre la transición de la alienación a la libertad, un movimiento producido por la liberación pedagógica. Se discute cómo describir la experiencia de proximidad entre seres humanos como experiencia de la historia popular y por fin reflexiona sobre la importancia de remover los obstáculos que impiden la revelación del Otro, a través del pensamiento que sabe escuchar la palabra analéctica del Otro, comprometiéndose con la palabra reveladora y su justa interpretación.

PALAVRAS CLAVE: Alteridad. Dialogo. Derechos Humanos. Educación.

\footnotetext{
${ }^{1}$ Universidade Federal do Rio Grande (FURG), Rio Grande - RS - Brasil. Professor no Programa de PósGraduação em Educação Ambiental. Doutorado em Educação (UFPEL). ORCID: https://orcid.org/0000-00024566-3655. E-mail: dmtalcf@furg.br

${ }^{2}$ Instituto Federal Sul-Rio-Grandense (IFSUL), Pelotas - RS - Brasil. Professora no Programa de PósGraduação em Educação. Doutorado em Educação Ambiental (FURG). ORCID: http://orcid.org/0000-00019014-0071. E-mail: lucianel1968@gmail.com
}

RIAEE - Revista Ibero-Americana de Estudos em Educação, Araraquara, v. 16, n. 2, p. 666-681, abr./jun. 2021. e-ISSN: 1982-5587. DOI: https://doi.org/10.21723/riaee.v16i2.13521 
ABSTRACT: The text presents a critical descriptive study with approximations to the Enrique Dussel's thinking, based on a qualitative research of bibliographic character. The intention is to list the assumptions that demonstrate the importance of the category otherness so that it is possible to reflect on the construction of life projects for the Latin American people, bringing together the ideas worked in the area of education. It is reflected in the text on the transition from alienation to freedom, a movement produced by pedagogical liberation. It discusses how to describe the experience of proximity between human beings as an experience of popular history and finally reflects on the importance of removing the obstacles that prevent the revelation of the Other through thinking that knows how to listen to the Other's word analectical committing to the revealing word and its fair interpretation.

KEYWORDS: Otherness. Dialogue. Human Rights. Education.

\section{Considerações iniciais}

Parte-se da premissa de que o sofrimento do Outro passa a existir em uma dada realidade no momento em que determinados sujeitos subjugam os outros, ou seja, os oprimem, por meio de relações assimétricas de poder. Nessas condições, o que está em questão é o conjunto dos direitos humanos desses sujeitos oprimidos, os quais devem ser reinventados a partir de processos de lutas próprios inseridos em sua cultura, tal que sejam renovados na práxis da libertação, evitando, assim, que sejam ideologizados como mecanismos de opressão.

Nessa linha de raciocínio, é indispensável que se promova a universalidade dos direitos humanos a partir dos processos de luta próprios de cada cultura, tal que o movimento da Filosofia da Libertação instituiu-se como fundamental para fazer pensar os direitos humanos das culturas latino-americanas, considerando a própria realidade em questão, partindo da opção pela libertação dos povos oprimidos.

É a partir desses fundamentos que se constituiu a obra de Enrique Dussel. O filósofo argentino, no início dos anos 70, juntamente com outros intelectuais, fundou, conforme anunciado, a Filosofia da Libertação, movimento esse comprometido com a libertação do povo pobre e excluído, correlacionado, ainda, ao movimento da Teologia da Libertação. Os movimentos geraram à época o estudo de uma filosofia mundial contrária ao eurocentrismo, associado a uma reflexão do povo sobre a práxis para uma ação libertadora, provocando ameaças e perseguições ao autor.

O ano de 1975 foi decisivo para o exílio de Dussel, pois nesse ano, diante dos conflitos sociais, econômicos e políticos vividos na Argentina, articularam-se os grandes ensaios de cerceamento dos direitos humanos no momento em que as Forças Armadas argentinas 
conseguiram do governo constitucional de María Estela Martínez Perón, Isabelita Perón, o encargo de articular a repressão no país. O ano de 1975 foi considerado o anúncio para o golpe no ano seguinte, em março de 1976, o qual instalaria na Argentina um governo autoritário e antidemocrático semelhante a outros já em curso na América do Sul.

Nessa época, as obras de Dussel foram proibidas na Argentina e a sua retirada se fez necessária com o ato posterior de radicar-se no México. Nesse país, o mesmo autor continuou susas reflexões remetendo à Teologia e à Filosofia da Libertação. Para Dussel (1995), a primeira experiência da Filosofia da Libertação remete a descobrir os fatos opressivos, os quais geraram a dominação em que determinados sujeitos se constituíram senhores de outros. Para o mesmo autor, são os seguintes: I) Plano mundial: centro - periferia, a partir da expansão europeia em 1492; II) Plano nacional: elites - massas, burguesia nacional, operário e povo; III) Plano erótico: seres humanos - relações entre homens e mulheres; IV) Plano pedagógico: cultura imperial e elitista versus cultura periférica e popular; e V) Plano religioso: o fetichismo em identificar na estrutura do sistema a natureza do ser humano como essência daquilo que a divindade decidir.

No momento em que Dussel $\left(1977^{a}\right.$, p. 134) remete aos níveis concretos da ética latino-americana, a partir do plano pedagógico, o faz iniciando pela situação concreta, de tal maneira que afirma que o caminho para destruir as "[...] ataduras da liberdade do outro" é pelo exercício da atitude crítica em que um ser humano chama o Outro a recuperar a sua atitude pessoal.

Ao utilizar a dimensão pedagógica Dussel o faz em um sentido amplo, para além da ciência da aprendizagem, como a parte da filosofia a qual reflete e estuda sobre as relações, pai-filho, mestre-discípulo, político-cidadão, dentre outras inseridas no contexto cultural.

Nessas condições, aproximando-se as atividades do educador, reflete-se que esse ser humano, ao chamar o Outro, o educando, a recuperar sua atitude torna-se um sujeito novo e vive, antecipadamente, a proximidade do face-a-face ${ }^{3}$.

Para o mesmo autor, no contexto educativo o educador deve negar a totalidade fechada, pois essa instaura sempre a novas dominações, e de outra maneira abri-la a alteridade, tal que a passagem da alienação a liberdade se produza pelo caminho da libertação pedagógica.

${ }^{3}$ A metafísica do face-a-face no contexto dusseliano representa a exterioridade do mestre e do discípulo, do pai diante do filho, em que a alteridade é constitutiva originária e essencial ao mundo da totalidade e, dessa maneira, “[...] 'o Outro' é prévio à invenção a partir de 'o Mesmo'” (DUSSEL, 1977a, p. 131, grifos do autor). 
Partindo da situação concreta, pela atitude crítica, no exercício da autoconsciência sobre a alienação, reconhecendo, ainda, sofrer a dominação e pensando a opressão e a libertação, é que os seres humanos caminham dialeticamente em direção a um novo projeto, conduzidos pela palavra do Outro. Com o objetivo de refletir sobre a construção desse novo projeto, aproximando, ainda, as ideias trabalhadas à área da Educação, esse trabalho tem por intencionalidade apresentar um estudo sobre o pronunciar e o transformar o mundo com ênfase na categoria alteridade, a partir dos pressupostos de Enrique Dussel.

$\mathrm{O}$ texto está descrito da seguinte maneira: $\mathrm{O}$ face-a-face como modo de compreensão ontológica - faz-se uma reflexão de que a passagem da alienação à liberdade se produz pela libertação pedagógica, no momento em que se nega a totalidade fechada e se tenta abri-la à alteridade; A libertação do pensamento latino-americano - problematiza-se o pensamento latino-americano em que não é possível descrever a experiência da proximidade entre os seres humanos como experiência individual, mas como experiência da história popular; A educação e a cultura latino-americanas - compreende-se que o povo latino-americano foi instruído em uma cultura estranha, alheia à tradição popular a qual foi subsumida; e A alteridade e a interpretação da voz do Outro - reflete-se sobre a importância de destituir os obstáculos que impedem a revelação do Outro, por meio de um pensar que sabe escutar a palavra analética do Outro, compromentendo-se com a palavra reveladora e a sua justa interpretação. Após seguem as considerações finais e as referências.

\section{O face-a-face como modo de compreensão ontológica}

$\mathrm{Na}$ ontologia da totalidade, o educador conserva uma posição passiva e não inovadora. Nessas condições, na totalidade se estabelece a dialética do Mesmo, pois se trata de uma categoria unidimensional, única, a qual define a partir do sujeito a identidade e a diferença, tornado-se o fim do discurso, impossibilitando o diálogo com alteridade.

Para Dussel (1977a, p. 131), a pedagogia, dessa maneira, torna-se apenas detentora do conhecimento, não permitindo a influência de outros elementos. $\mathrm{O}$ Mesmo tira de sua potência a atualidade do educando, destituindo o Outro como mestre, subsumindo a sua realidade, fazendo com que o Outro, supostamente, nada tenha a fazer no processo. "Na práxis o mestre grego e o moderno transmitiam com férreo sistema disciplinar a tradição histórica de seus respectivos mundos sem o respeito ao Outro".

De outra maneira, na metafísica do face-a-face, a pedagogia se faz prévia à ontologia, o Outro constitui-se prévio à invenção do Mesmo, tal que o educador (o Mesmo), ao proferir 
sua palavra, o faz como fruto de suas invenções próprias e de sua cultura, e ao mesmo tempo aprende sobre o projeto de vida do educando (o Mesmo do Outro que o educador ignorava) e passa a conhecer a sua realidade.

Daí que, nessas condições, o educando aprende a palavra autêntica do educador (o Mesmo do Outro que o educando desconhecia), lançando seu mundo (o Mesmo), seu projeto de vida, em movimentos que significam a sua própria realização.

Educador e educando sempre tem algo a aprender, e nesse processo, muito rapidamente, o educando começa a ensinar, pois nenhum “[...] discípulo é puramente discípulo; nenhum mestre é puramente mestre" (DUSSEL, 1977a, p. 133).

Assim, o aprendizado do educador está vinculado à novidade do projeto do jovem educando, a juventude do Outro, juventude essa que, para o autor, nunca é igual à do educador, porque se origina em outro momento da história. Por outro lado, o que o jovem educando aprende o faz a partir da alteridade do educador, sujeito esse que surge em seu mundo a partir da anterioridade da humanidade como Outro.

$\mathrm{O}$ ato de ensinar está para além do simples ato de estudar o que, anteriormente, já foi trabalhado, de tal forma que não se transmite o tradicional como tradicional, mas se estuda o modo como o conhecimento foi alcançado de maneira crítica. Revive-se, assim, um conjunto de condições que tornam possível o novo, o único, ou, ainda, a criação.

Na concepção de Dussel (1977a, p. 134, grifo do autor), o exercício do autêntico magistério é arriscado, pois representa uma práxis, um compromisso existencial. O autor afirma que na dialética degradada o educador transforma-se no Se impessoal e o educando no Isto, também impessoal, como aquele que “[...] se deve 'encher' de conhecimentos 'tradicionais', 'seguros', 'objetivos'”.

O autêntico educador propõe um caminho inverso ao da dialética degradada, tal que, em posição crítica, chama o Outro, o educando, a recuperar a sua atitude pessoal e, nessas condições, o educador já é um novo ser humano, vivendo, antecipadamente, a proximidade do face-a-face.

Dussel (1977a) reafirma sua proposição de que a passagem da alienação à liberdade se produz pela libertação pedagógica, no momento em que se nega a totalidade fechada e se tenta abri-la à alteridade. 


\section{A libertação do pensamento latino-americano}

O ponto central da reflexão em Dussel é a compreensão sobre a necessidade de que ocorra uma libertação do pensamento latino-americano no intuito de permitir concretizar a libertação do trabalhador explorado. De igual forma, para o mesmo autor, é reconhecido que esse pensamento, ainda na contemporaneidade, mantém-se submisso à filosofia europeia.

No momento em que Dussel (2000, p. 51) remete ao paradigma eurocêntrico afirma que o fenômeno da modernidade 4 “[...] é exclusivamente europeu, que vai se desenvolvendo desde a Idade Média e se difunde posteriormente em todo o mundo". Essa difusão do paradigma europeu, por meio dos processos de colonização, criou a ideia de independência e supremacia, associada a um conjunto de características internas que a Europa tivera, as quais permitiram que a mesma superasse outras culturas, essencialmente, pela sua racionalidade. " $\mathrm{O}$ ego moderno apareceu em sua confrontação com o não-ego; os habitantes das novas terras descobertas não aparecem como Outros, e sim como o Mesmo a ser conquistado, colonizado, modernizado, civilizado, como 'matéria' do ego moderno" (DUSSEL, 1992, p. 46, grifo do autor).

O paradigma alternativo, a partir do horizonte mundial, concebe que "[...] a modernidade europeia não é um sistema independente autopoiético, auto-referente, mas é uma 'parte' do 'sistema-mundo': seu centro. A modernidade, então é um fenômeno que vai se mundializando" (DUSSEL, 2000, p. 52, grifo do autor).

Nessas condições, a fillosofia deve pensar a realidade mundial, não a partir da perspectiva do centro, que detém os poderes político, econômico, científico ou militar, mas para além dessas fronteiras, ou seja, exercitar o pensar a partir da periferia, das condições dos condenados da terra ou, ainda, dos esfarrapados do mundo.

Fanon (1968, p. 29), ao comparar as condições sociais entre o colono ${ }^{5}$ e o colonizado (os condenados), reflete que a cidade do colonizado é uma cidade faminta de pão, de carne, de sapatos, de carvão, de luz, tal que se constitui como uma cidade "[...] acocorada, uma cidade ajoelhada, uma cidade acuada". Nessas condições, o contexto colonial estava fundamentado em uma realidade econômica desigual, tal que se criaram diferenças nos modos de vida, na própria cultura.

${ }^{4} \mathrm{O}$ acontecimento fundante da modernidade para Dussel (1992, p. 19, grifo do autor) foi o descobrimento da Ameríndia, a qual foi essencial na "[...] constituição do 'ego' moderno, porém não somente como subjetividade e sim como subjetividade 'centro' e 'fim' da história".

${ }^{5} \mathrm{O}$ colono conseguia, ainda, deturpar e envenenar os valores, costumes e tradições do colonizado, fazendo com que esses se tornassem pervertidos, o que acarretou no exercício da destituição e, consequentemente, destruição dessa cultura. 
Já Freire (2004) utiliza o termo esfarrapados ${ }^{6}$ do mundo ao refletir sobre uma ordem social injusta, opressor - oprimidos (esfarrapados), em que o primeiro, no exercício de uma falsa generosidade, mantém a estrutura opressora a qual se nutre da miséria e da própria falsa generosidade. Para o autor, é por meio da luta pela restauração da humanidade do oprimido que se poderá restaurar a generosidade verdadeira.

Retomando Dussel (2000), o autor afirma que a centralidade da Europa no sistemamundo não é fruto somente da superioridade interna acumulada na Idade Média europeia sobre as culturas, mas também o efeito do fato do descobrimento, da conquista, da colonização, da integração e da subsunção da Ameríndia, que proporcionaram à Europa uma vantagem comparativa sobre o mundo.

A Europa, ao longo dos anos, foi se organizando como a civilização capaz de conquistar o mundo, e ao descobrir e extrair os recursos da América foi se fortalecendo e se tornando um modelo para o resto do mundo.

A partir dessas colocações, enfatiza-se sobre a necessidade de refletir que mesmo antes de considerar a singularidade do Outro existe a história construída de um povo, o contexto desse povo, a sua cultura. Assim, o Outro como oprimido revela a história de um grupo de seres humanos tal que não é possível descrever a experiência da proximidade como experiência individual, mas como experiência da história popular. Na experiência pessoalcoletiva, o rosto do Outro se torna o "[...] rosto de um sexo, de uma geração, de uma classe social, de uma nação, de um grupo cultural, de uma idade da história” (DUSSEL, 1977c, p. $50)$.

O ser humano como Outro é aquele que representa o centro do seu próprio mundo, e mesmo como dominado ou oprimido pode vir a dizer o inesperado, o inédito, a palavra que representa a experiência pessoal-coletiva, em seu mundo. Assim, enquanto outro é um ser livre, já enquanto parte de um sistema torna-se funcional em relação a uma estrutura.

Dussel $(1977 \mathrm{c})$ reflete que no momento em que é possível desprezar a exterioridade do Outro como o nada, a incultura, o analfabetismo, a barbárie, ou, ainda, como o nulo, remetese à possibilidade de surgimento da história desse povo. Para o mesmo autor, é nesse momento que aparece a novidade e se criam, em sentido metafísico, os novos sistemas.

$\mathrm{O}$ ato de aceitar a palavra do Outro é porque essa o revela sem outro motivo, pois é o resultado de sua pronúncia. “O que me revela não tem outro critério de certeza a não ser a 
própria realidade do outro como outro" (DUSSEL, 1977c, p. 52-53). A partir dessas ideias o ato de revelar é expor-se e o crer é lançar-se no vazio.

Tal situação irá garantir a convivência com o direito às diferenças, sem que se exclua o debate, ou seja, o diálogo sobre as diferenças. As diferenças estão, justamente, nos contextos vividos pelos seres humanos, em sua cultura, tal que a experiência dialógica se torna uma experiência individual-coletiva.

\section{A educação e a cultura latino-americanas}

Ao resgatar a cultura pré-hispânica, Dussel (1977b, p. 159) reflete que o ser humano é educado na cultura, na totalidade simbólica de seu povo, em que estão presentes o domínio de seus instintos e da natureza. Dessa maneira, a educação é levada à frente em cada família, em todo o povo. "Era proverbial a eficácia da educação pré-hispânica, quanto ao cumprimento das regras sexuais, a veracidade da palavra, o respeito ao bem alheio".

$\mathrm{O}$ choque entre as culturas, europeia e ameríndia, fez com que o europeu, o conquistador, se tornasse o opressor, pois na guerra foram deixados vivos, somente, jovens e mulheres. Para Dussel, o processo erótico latino-americano se originou pela dominação que o conquistador exerceu sobre a índia, bem como o processo político teve a sua origem na dominação do espanhol sobre o índio, por meio da matança, pela guerra.

Já a dominação pedagógica começou pelo proselitismo que antecedeu ou seguiu a conquista e não pela evangelização independente ${ }^{7}$ da conquista. $\mathrm{O}$ fenômeno da aculturação foi produzido na cultura ameríndia no momento em que passaram a ser trabalhados os fundamentos hispânico-europeus cristãos como novos conteúdos históricos. Assim, a pedagógica latino-americana fundamentou-se em uma dominação ideológica e de geração em geração foi criando uma nova cultura.

Essa nova cultura, por sua vez, ignorou a si mesma, tratando-se como distinta, na qual se fez presente a tríplice contradição: “[...] presença da cultura imperial europeia ou do 'centro', da cultura ilustrada da oligarquia encomendera, da cultura popular dos mestiços, negros, índios, cafuzos, etc" (DUSSEL, 1977b, p. 162, grifo do autor).

Acrescente-se a esses fatos o peso sobre a cultura popular latino-americana do juízo que o colono fazia dos colonizados, tal que o colono imputou "[...] que a preguiça é constitutiva da essência do colonizado" (MEMMI, 2007, p. 119). Para o mesmo autor, isso

${ }^{7}$ Bartolomeu de Las Casas reflete sobre um processo de evangelização pacífico sem o uso da guerra, contrário à colonização. Para Dussel (1977b), esse processo está diretamente vinculado à conquista, ou seja, à submissão do índio, em função da guerra. 
fez com que por melhor que o colonizado fosse, ou que, ainda, assumisse alguma função de trabalho, nunca passasse de ser um simples ocioso.

Outra característica definida para o colonizado é de que este era débil e que, por isso, demandava proteção. O colono acrescentou que "[...] o colonizado é um retardado perverso, com maus instintos, ladrão, ligeiramente sádico" (MEMMI, 2007, p. 120) para, dessa maneira, poder legitimar sua severidade. Entre os principais argumentos do colono para agir com severidade é que se fez necessário defender o colonizado contra si mesmo e, ao mesmo tempo, que esse era inapto à técnica e ao progresso, tratando-o como aquele sem sabedoria.

Esse juízo da cultura popular penetrou na pedagógica latino-americana, constituindo uma pedagógica que acabou por trair um passado, uma história, e determinou, ao fim, a dominação do povo.

Por outro lado, passaram a surgir, no século XIX, as lutas de emancipação colonial, as quais começaram a produzir rupturas nessas condições. Assim, surgiu na América Latina um tempo em que duas civilizações conviveram no mesmo solo: uma nascente como aquela sem conhecimento e que passou a imitar os esforços populares da Idade Média, e a outra como aquela que tentou realizar os resultados da civilização europeia. O projeto dessa última consistia em introjetar no povo uma cultura ilustrada, a cultura da burguesia dependente, negando a cultura popular, a cultura do gaúcho Fierro. Hernández (1987) reconfigura seu pretenso herói ao desvelar as misérias do gaúcho pampeano, oportunizando a desconstrução do mito regional. Para o mesmo autor, o gaúcho é visto como um degradado despido de qualquer dignidade.

Desse modo, repetiu-se a dialética da conquista em que o latino-americano constituiuse como um servo do novo sistema, tal que esse sujeito passou a ser instruído em uma cultura estranha, alienante da tradição popular. A escola reproduzia a cultura da burguesia enfatizando a contradição nas colônias, em que a elite ilustrada se constituia em oposição à cultura popular, não aceitando sua pedagógica ontológica.

A pedagógica moderna, como aquela que se rebelou contra a pedagógica da autoridade medieval, formou-se, inicialmente, tendo como meta a organização da disciplina da cristandade latino-germânica, concentrando-se em um sistema educativo de rendimento e eficácia. Esse sistema propunha que a censura fosse introjetada no interior da subjetividade culpada e, dessa maneira, produziu-se uma estrutura pedagógica em que o educando foi despossuído diante da autoridade, autoridade essa que determinou a primazia das leis divinas e naturais sobre as leis humanas. 
Posteriormente, levantou-se uma nova pedagógica, com a burguesia em ascenção, momento em que se instaurou, centrado na categoria trabalho, um sujeito cuja autoconsciência constitutiva era a da burguesia em expansão. Assim, a cultura popular ficou subsumida a essa cultura particular, servindo aos interesses históricos então constituídos.

A partir desses pressupostos, Dussel (1977b) propõe a utilização da metáfora do conflito famíliar do ponto de vista psicanalítico, para análise das questões da época. Inicialmente, o estado colonial é simbolizado pelo pai, preceptor a soldo do estado imperial. A cultura popular é simbolizada pela mãe, mulher-cultura, a qual totaliza os seus filhos, ou seja, a cultura popular amamenta em seus símbolos os seus filhos, tentando preservá-los do estado burguês e de sua pedagogia.

Nessas condições, o pai, estado colonial, a serviço do estado imperial, interpõe-se entre a mãe-cultura popular e o filho-povo, daí que nascerá o ódio ao pai-estado, a situação edípica $^{8}$. A superação ocorre pela negação da mãe-cultura e pela identificação com o paiestado, pois o "[...] filho-povo ao negar sua mãe-cultura popular, fica órfão (ente orfanal como o chamamos) à disposição do pai-Estado que se mascara por trás do rosto amigo e severo do preceptor, o ego magistral" (DUSSEL, 1977b, p. 173, grifo do autor).

O preceptor, o estado imperial, traz consigo a noção de exploração da natureza no ato de crer que essa seja universal e eterna, ou seja, o burguês que se relaciona beneficiando-se da natureza, o que faz com que a pedagógica moderna eduque o filho-povo como se esse não possuísse conhecimentos, mesmo porque o filho-povo acaba por não ter uma família que o pré-determine, é destituído de sua cultura popular e, ainda, negado de um pai opressor. O que resta a esse filho-povo é a repressão pela dominação pedagógica que se exerce sobre ele.

Assim o preceptor tem em seu poder o filho-povo, ocupando o lugar dos pais, na ação de suprir as debilidades desse filho, negando a cultura anterior e oprimindo a popular. A subjetividade desse filho é objetivada e seu mundo sendo, assim, manipulado com a pretensão de respeitar a sua própria liberdade. É exigido desse filho que seja livre dos condicionamentos do pai, da mãe e da cultura e, por fim, será conduzido a um projeto pré-existente burguês.

Essa subjetividade compreende o ser, um projeto de homem europeu buguês, aquele que vive no centro. "O pai-Estado-mestre é o ego, o ponto de apoio, o 'de onde' se desdobra o

\footnotetext{
${ }^{8} \mathrm{Na}$ teoria psicanalítica o complexo de Édipo ocorre durante o estágio fálico do desenvolvimento psicossexual, entre crianças, aproximadamente de 3 a 6 anos, momento em que ocorre a formação da libido e do ego. É o primeiro estágio em que as crianças tornam-se conscientes das diferenças sexuais. O termo complexo de Édipo é inspirado na tragédia grega Édipo Rei, a qual designa o conjunto de desejos amorosos e hostis que o menino enquanto ainda criança experimenta com relação a sua mãe.
} 
círculo pedagógico, ideológico, de dominação gerontocrática sobre a criança, a juventude, o povo" (DUSSEL, 1977b, p. 179, grifo do autor).

Para o autor, o órfão da pedagógica da dominação não é somente a criança, mas a criança da periferia, o órfão colonial, neocolonial e, ainda, o mestiço latino-americano, resultantes de uma luta desigual entre a civilização europeia conquistadora e o povo ameríndo.

\section{A alteridade e a interpretação da voz do Outro}

A alteridade é uma categoria fundamental no contexto dusseliano, tal que se caracteriza como a "[...] passagem diacrônica, desde o ouvir a palavra do outro até a adequada interpretação" (DUSSEL, 1986, p. 208) do mesmo, de acordo com uma ética pressuposta no ser humano. Dussel afirma-se no exercício do ouvir o Outro, pelo compromisso existencial, em que a filosofia é o pensar reduplicativamente a palavra do Outro, injetando-lhe nova possibilidade a partir da consciência crítica do próprio Eu.

Para o mesmo autor, é pelo compromisso existencial, pela práxis libertadora, por um tornar próprio o mundo do Outro que é possível alcançar a interpretação, a conceitualização e a verificação de sua revelação. Nesse momento, em que se caminha em direção à libertação do Outro, é que se alcança a própria.

Deve-se considerar a palavra do Outro como "semelhante", conservando a distinção metafísica que se apoia nele como Outro, não como idêntico ou unívoco, mas respeitando a analogia da revelação.

Assim, a história da libertação humana se faz a partir de resultados relativos, nunca finais, de tal maneira que para Dussel (1986, p. 209) o caminho é ouvir a voz do pobre, a voz do povo, comprometendo-se com a "[...] humildade e mansidão na aprendizagem pedagógica do caminho de que a palavra do outro, como mestra, vai traçando cada dia".

Partindo da situação concreta, pela atitude crítica, no exercício da autoconsciência sobre a alienação, reconhecendo, ainda, sofrer a dominação e pensando a opressão e a libertação é que os seres humanos caminham dialeticamente em direção a um novo projeto, conduzidos pela palavra do Outro.

Com o objetivo de refletir sobre a construção desse novo projeto, a filosofia, originariamente analética, caminha dialeticamente conduzida pela palavra do Outro. Para o mesmo autor, o começo para esses movimentos está na confiança, “[...] na fé, no magistério e na verdade do outro: hoje é confiança na mulher, na criança, no operário, no subdesenvolvido, 
em uma palavra, no pobre: ele, o aluno, tem o magistério" (DUSSEL, 1986, p. 209, grifo do autor).

A filosofia, nessas condições, é propriamente pedagógica no momento em que se constitui uma relação a partir do método que saber é crer na palavra do Outro e, de mesma maneira, é interpretá-la. O educador para ser um verdadeiro mestre deverá ser discípulo do futuro discípulo, do futuro educando, condição basilar para o exercício da interpretação de uma pedagógica analética aberta à liberdade, pois, de modo contrário, somente na dialética da totalidade ontológica, o educador torna-se um escravo da totalidade fechada.

O educador que se compromete com a libertação concreta do Outro desvela um novo mundo em que é possível compreender outro momento de ser, vislumbrando um contexto histórico, social e cultural inédito.

Para Dussel, é a partir desssas condições que os povos latino-americanos poderão reconstituir um novo estatuto como seres humanos, por meio da exterioridade metafísica em relação àqueles que vivem no Atlântico Norte, elencando a fecundidade na alteridade como a categoria a qual promove que a voz da América Latina seja ouvida.

Retomando a discussão, os povos da América Latina são o filho da mãe ameríndia dominada pelo pai hispânico dominador. O filho, o Outro, é o oprimido pela pedagogia dominadora da totalidade europeia, constituído como o primitivo e o subdesenvolvido, tal que nunca foi respeitado como o Outro. Assim, não respeitado e negado como ente conhecido, é dominado, pelo sistema, em sua exterioridade.

O que o educador deve ter presente é saber como destituir os obstáculos que impeçam a revelação do Outro, do povo latino-americano, tal que a filosofia latino-americana deve se constituir como o pensar que sabe escutar discipularmente a palavra analética, analógica do oprimido, “[...] que sabe comprometer-se como o movimento ou com a mobilização da libertação e, no próprio caminhar, vai pensando a palavra reveladora que interpela a justiça; isto é, vai a acedendo à interpretação precisa de seu significado futuro" (DUSSEL, 1986, p. 211).

Assim, o pensar como a pedagogia analética da libertação é um clamor, como a exortação do mestre que faz reincidir sobre o discípulo a objeção que antes havia recebido como revelação reduplicadamente criadora. "A filosofia latino-americana, que tende à interpretação da voz latino-americana, é um momento novo e analógico na história da filosofia humana" (DUSSEL, 1986, p. 211).

Para o mesmo autor, a filosofia do povo latino-americano é analogicamente semelhante (como parte de uma etapa histórica) e distinta (como original e inimitável) porque 
pensa a voz única de um novo Outro como palavra a ser revelada, palavra essa que nunca foi ouvida ou interpretada.

Não se deve confundir o ser semelhante com a identidade da univocidade, mas contemplar o distinto para que se crie um momento analógico que nasce após a modernidade europeia, tal que a cultura possa expressar o que lhe é próprio na universalidade, que não remete somente à universalidade abstrata ${ }^{9}$ nem tampouco à universalidade concreta ${ }^{10}$.

\section{Considerações finais}

Os pressupostos presentes no pensamento de Enrique Dussel remetem à reflexão sobre a necessidade de valorização da identidade cultural dos seres humanos, especificamente do povo latino-americano, identidade essa que anuncia a leitura de mundo exercida por esses sujeitos, não raro, subsumida a uma cultura dominante, a cultura europeia.

A discussão elaborada no texto enfatizou a necessidade de respeito e entendimento diante dos saberes do povo latino-americano, o que remete ao exercício de um diálogo, com a premissa na necessidade de ouvir o Outro, deixando tomar-se pelas suas razões, antes de elaborar a contraposição de ideias, ou seja, o deixar algo em si que foi dito pelo Outro, o exercício da alteridade.

Trata-se de um processo coletivo que permite aos seres humanos refletirem sobre as suas possibilidades e potencialidades, diante de um aprender melhor o que já sabem sobre seu mundo, aprendendo a criar conhecimento que venha a ser promotor das ações almejadas das transformações sociais.

Com o foco voltado ao campo da educação socio-histórica e crítica enfatizam-se a necessidade de respeito e entendimento diante dos saberes dos sujeitos, tal que essa educação crítica assume seu papel no momento em que marcha na direção da constituição de uma nova realidade e, ao mesmo tempo, denuncia as estruturas desumanizantes.

De maneira resumida, refletiu-se a respeito das seguintes categorias:

- A dialética - da qual se assume a importância da história, bem como do papel da objetividade e da subjetividade humana na construção do mundo socioculturalmente estruturado. Enfatiza-se que a dialética deverá possuir um ponto de apoio analético;

${ }^{9}$ Dussel (1986) remete a um totalitarismo de um particularismo abusivamente universalizado.

${ }^{10}$ Dussel (1986) compreende a consumação unívoca da dominação.

RIAEE - Revista Ibero-Americana de Estudos em Educação, Araraquara, v. 16, n. 2, p. 666-681, abr./jun. 2021. e-ISSN: 1982-5587. DOI: https://doi.org/10.21723/riaee.v16i2.13521 
- O diálogo - cuja exigência é a escuta de uma prática, de tal maneira que a relação dialógica priorize a vocação de ser sujeito, promovendo a compreensão do contexto e dos saberes dos envolvidos na relação;

- A analética - como a promoção da passagem ao justo crescimento da totalidade dialética desde o Outro, respeitando esse sujeito criativamente, por meio de um saber ouvir a voz produzida por ele; e

- A alteridade - da qual a premissa é a necessidade de ouvir o Outro e, conforme já anunciado, o deixar tomar-se pelas razões do Outro, como o deixar algo em si que foi dito pelo Outro.

A ideia de que a partir do desenvolvimento das relações com a realidade, integrado ao contexto e associado a uma consciência crítica, é que torna possível, pela relação dialógica fundamentada na alteridade, compreender o ser humano como aquele que humaniza essa mesma realidade e, ao mesmo tempo, como ser agente no e com o mundo, no intuito de tornar-se reconstrutor da cultura.

A partir dos pressupostos aqui explicitados, reafirma-se que os fundamentos da obra de Enrique Dussel aproximados ao campo da educação crítica representam um marco conceitual capaz de oferecer sustentação à formação dos seres humanos, formação essa imbricada à transformação social, tal que a apreensão das determinantes históricas seja o foco dessa formação.

Daí que, situando a práxis educativa por argumentos dusselianos, faz-se a opção por outro agir na ação educativa. Distanciando-se das práticas opressoras, educador e educandos não se expressam por dicotomias instituídas na opressão de quem manda e na submissão de quem obedece, mas pelo exercício da alteridade, quando se propõem voz e vez aos sujeitos envolvidos.

Acredita-se que, para o educador, esses momentos se tornem ricos na relação educativa, possibilitando conhecer os educandos envolvidos e suas percepções de mundo. Sempre que os educandos se percebem ouvidos e, consequentemente, inseridos na relação, exercitam os primeiros passos, como experiências democráticas, em direção à tomada da consciência crítica.

Dessa maneira, esses movimentos abrem as portas ao relato de diferentes visões de mundo, aportando os fragmentos referentes à cultura na qual educador e educandos estão imersos. Promove-se, nesse sentido, a partilha, a qual exercita a reflexão. 
A relação educativa, na Pedagogia da Libertação, realiza-se inserida na práxis, fundamentada na humanização, objetivando a libertação dos sujeitos, de modo que o "[...] ato pedagógico crítico se exerce no próprio sujeito e na sua práxis de transformação: a libertação assim é 'lugar' e o 'propósito' desta pedagogia” (DUSSEL, 2000, p. 443, grifo do autor).

Por fim, retomando as questões aqui apresentadas sobre a cultura latino-americana, a proposta de Dussel não é ingênua, e reconhece, ao mesmo tempo, a dificuldade europeia em aceitar essa posição filosófica, pois essa mesma coloca em questão a pretensa universalidade da Europa e seus prolongamentos culturais do Atlântico Norte. Para o mesmo autor, a ideia é pensar uma “[...] 'filosofia bárbara', uma filosofia que surja a partir do 'não ser'” (DUSSEL, 1986, p. 213, grifo do autor).

\section{REFERÊNCIAS}

DUSSEL, E. 1492: el encubrimiento del outro - hacia el origen del mito de la modernidad. 1. ed. Madrid: Nueva Utopia, 1992.

DUSSEL, E. Ética da libertação na idade da globalização e da exclusão. 1. ed. Petrópolis: Vozes, 2000.

DUSSEL, E. Filosofia da libertação: crítica à ideologia da exclusão. 1. ed. São Paulo: Paulus, 1995.

DUSSEL, E. Filosofia da libertação: filosofia na América Latina. 1. ed. São Paulo: Loyola, $1977 \mathrm{c}$.

DUSSEL, E. Método para uma filosofia da libertação: Superação analética da dialética hegeliana. São Paulo: Loyola, 1986.

DUSSEL, E. Para uma ética da libertação latino-americana: acesso ao ponto de partida. 1. ed. São Paulo: Loyola, 1977a. v. 1.

DUSSEL, E. Para uma ética da libertação latino-americana: Erótica e pedagógica. 1. ed. São Paulo: Loyola, 1977b. v. 3.

FANON, F. Condenados da terra. 1. ed. São Paulo: Civilização Brasileira, 1968. v. 42.

FREIRE, P. Pedagogia do oprimido. 38. ed. São Paulo: Paz e Terra, 2004.

HERNÁNDEZ, J. Martín Fierro. Porto Alegre: Martins, 1987.

MEMMI, A. Retrato do colonizado precedido do retrato do colonizador. 1. ed. Rio de Janeiro: Civilização Brasileira, 2007. 


\section{Como referenciar este artigo}

FREITAS, A. L. C.; FREITAS, L. A. A. A alteridade no plano pedagógico a partir dos pressupostos de Enrique Dussel. Revista Ibero-Americana de Estudos em Educação, Araraquara, v. 16, n. 2, p. 666-681, abr.jun. 2021. e-ISSN: 1982-5587. DOI: https://doi.org/10.21723/riaee.v16i2.13521

Submetido em: 30/03/2020

Revisões requeridas em: 20/07/2020

Aprovado em: 13/08/2020

Publicado em: 01/02/2021 